DOI: 10.17516/1997-1370-0772

УДК 378.147

\title{
Mutual Integration of Information and Mathematical Training for Engineers in the Digitization Era
}

\author{
Viktor A. Dalingera, Natalya A. Moiseeva ${ }^{\mathrm{b}}$ \\ and Tatyana A. Polyakova*c \\ ${ }^{a}$ Omsk State Pedagogicalt University \\ Omsk, Russian Federation \\ ${ }^{b}$ Omsk State Technical University \\ Omsk, Russian Federation \\ 'Siberian State Automobile and Highway University \\ Omsk, Russian Federation
}

Received 24.04.2021, received in revised form 14.05.2021, accepted 15.06.2021

\begin{abstract}
The article is devoted to the study of the development of interdisciplinary integration on the example of the disciplines «Computer Science» and «Mathematics» in training future engineers in the digitization era. It is considered the trends and directions for development of engineering education at the world level, among which a special role is given to the CDIO approach for implementing interdisciplinary training of future engineering personnel on the base of student-centered learning. It is revealed that information and mathematical modeling is the system-forming factor in the integration of knowledge in Computer Science and Mathematics. It is proposed a classification of IMM on the basis of which it is possible to create integrated educational and practical tasks with interdisciplinary content. In the experimental part of the research methods of questionnaire, survey, experiment are involved. In order to realize mutual integration of information and mathematical training the authors developed the scheme of implementation of the models in independent work of students throughout the entire training at ecosystem of technical university. It is defined student-centered learning technology and it is formulated the methodological recommendations for its implementation of the processes of mutual integration of the disciplines in the process of its teaching to students of engineering specialties of universities.
\end{abstract}

Keywords: engineering education, digitization, student-centered learning, computer science, mathematics, information and mathematical model, interdisciplinary integration, independent work, students' research work.

Research area: pedagogy.

\footnotetext{
(C) Siberian Federal University. All rights reserved

* Corresponding author E-mail address: nat_lion@mail.ru, dalinger@omgpu.ru, ta_polyakova@mail.ru ORCID: 0000-0003-0281-4422 (Dalinger); 0000-0002-9502-3891 (Moiseeva); 0000-0002-9673-1750 (Polyakova)
} 
Citation: Dalinger, V.A., Moiseeva, N.A., Polyakova, T.A. (2021). Mutual integration of information and mathematical training for engineers in the digitization era. J. Sib. Fed. Univ. Humanit. soc. sci., 14(9), 1399-1419. DOI: 10.17516/1997-1370-0772.

\title{
Взаимная интеграция
}

\section{информационно-математической подготовки инженеров в эпоху цифровизации}

\author{
В.А.Далингер ${ }^{\text {a }}$ Н.А. Моисееваб ${ }^{6}$ Т.А. Поляковав \\ ${ }^{a}$ Омский государственный педагогический университет \\ Российская Федерация, Омск \\ ${ }^{6}$ Омский государственный технический университет \\ Российская Федераџия, Омск \\ ${ }^{8}$ Сибирский государственный автомобильно-дорожный университет \\ Российская Федерачия, Омск
}

\begin{abstract}
Аннотация. Статья посвящена исследованию проблемы развития межпредметной интеграции на примере дисциплин «Информатика» и «Математика» при подготовке будущих инженеров в эпоху цифровизации. Рассмотрены тенденции и направления развития инженерного образования на мировом уровне, среди которых особая роль отводится концепции CDIO для реализации междисциплинарного обучения будущих инженерных кадров на студентоцентрированной основе. Выявлено, что системообразующим фактором интеграции знаний по информатике и математике выступает информационно-математическое моделирование. Предложена классификация информационно-математических моделей, на основе которой возможно создавать интегрированные учебно-практические задания междисциплинарного содержания. В экспериментальной части исследования задействованы методы анкетирования, опроса, эксперимента. С целью реализации взаимной интеграции информационно-математической подготовки разработана схема применения информационно-математических моделей в самостоятельной работе студентов на протяжении всего обучения в экосистеме технического вуза, определены студентоцентрированные технологии обучения и сформулированы методические рекомендации к осуществлению процессов взаимной интеграции рассматриваемых дисциплин в процессе их преподавания студентам инженерных специальностей вузов.
\end{abstract}

Ключевые слова: инженерное образование, цифровизация, студентоцентрированное обучение, информатика, математика, информационно-математическая модель, межпредметная интеграция, самостоятельная работа, научно-исследовательская работа студента.

Научная специальность: 13.00.00 - педагогические науки. 


\section{Введение}

Стремительное внедрение концепции «Индустрия 4.0» обусловило динамику развития цифровой экономики, порождающей новые экономические и технологические потребности, для реализации которых требуются высококвалифицированные инженерные кадры, готовые к изменениям и непрерывному обучению в течение всей жизни в новых условиях информационного общества. При этом цифровая трансформация находит свое отражение и в сфере образования, в том числе инженерного. Университет рассматривается в качестве «цифровой образовательной экосистемы» (Education, 2018), внутри которой осуществляется переход к образованию, главной отличительной чертой которого является ориентация на студента. В этом случае речь идет о студентоцентрированной направленности обучения как основополагающем принципе в современной образовательной парадигме, заложенном в образовательные стандарты нового поколения (Baidenko, 2018; Drozdova, Lobanov, 2007; Education, 2018; Hannafin, Hannafin, 2010; Nosko, 2011; Pak et al., 2015; Pak et al., 2017; Student-Centred Learning, 2010; Vaganova, Iliashenko, 2018; Wright, 2011). Выпускник вуза должен обладать креативным и критическим мышлением, быть ориентированным на непрерывное развитие, самоорганизацию своей деятельности, направленной на создание инновационного продукта.

В связи с чем в настоящее время одной из приоритетных тенденций развития высшего инженерного образования становится подготовка студентов к самообразованию и самоорганизации на основе студентоцентрированных технологий обучения, что соответствует требованиям подхода Международного общества инженерной педагогики (IGIP) и цели внедрения идеи концепции инновационного подхода CDIO (англ. Conceiving - Designing - Implementing Operating, «планировать - проектировать производить - применять»), предполагающего практико-ориентированную модель организации учебного процесса в инновационном инженерном образовании. В эпоху цифровой трансформации экономики и об- щества инженерная деятельность заключается в проектировании, конструировании и разработке современных технических объектов, оптимизации и инжиниринга инновационных производственных процессов, внедрении наукоемких и передовых цифровых технологий, в основу которых положены математические методы, реализованные на базе информационно-коммуникационных технологий (ИКТ). Это предъявляет к профессиональным и цифровым компетенциям инженера требование сформированности умений применять информационно-математическое моделирование для решения профессиональных задач. А потому подготовка будущих инженеров в технических вузах на современном этапе должна быть ориентирована преимущественно на формирование и развитие именно этих умений (Moiseeva, Poliakova, 2018; Noskov, Popova, 2015). Поскольку значительная роль в решении соответствующей задачи отводится совершенствованию методики обучения дисциплинам «Информатика» и «Математика» в контексте их взаимной интеграции, то один из основных вопросов, который ставят перед собой авторы настоящей статьи, - исследование вопросов осуществления межпредметной интеграции на уровне не только знаний, но и видов деятельности.

На сегодняшний день тенденции развития инженерного образования во всем мире основаны на внедрении подхода CDIO (Taajamaa et al., 2016; Yasseri et al., 2018; Zabalawi, 2018, etc.) и подхода к подготовке инженера, выработанного международным обществом инженерной педагогики IGIP (Auer et al., 2013; Auer, 2014; Prikhod'ko, Solov'iev, 2013, etc.). Направленность CDIO: «основным способом обучения выступает включение в основные образовательные программы (ООП) учебно-практических заданий-проектов (индивидуальных или групповых)» (Klarin, 2018) или «интегрированных учебно-практических заданий (ИУЗ), имеющих междисциплинарное содержание» (Fedoseev, 2016); введение проблемного и проектного обучения (Krasavina, 2017; Yasseri, 2018). При этом особая роль в контексте данного подхода к обучению 
отводится вопросам осуществления междисциплинарной интеграции и студентоцентрированному обучению, с которыми связаны перспективы развития инженерного образования (Chuchalin, 2018; Dolzhenko, 2017; Fedoseev, 2016; Krasavina, Shikhova, 2017; Perminov et al., 2019; Rodionov et al., 2018; Vainshtein et al., 2016; Verbiczkii, 2010). Направленность подхода IGIP: «умение учить и учиться является ключевым моментом эволюционного развития общества» (Auer, 2013), поэтому будущий инженер должен обладать способностью к самообразованию и самоорганизации.

\section{Обзор литературы}

Проблема смены образовательных парадигм в сторону студентоцентрированного характера образовательного процесса в настоящее время активно обсуждается в мировой научной образовательной среде. Особенности технологий студентоцентрированного обучения представлены в работе (Student-Centred Learning, 2010), являющейся частью проекта «Время новой парадигмы в образовании: студентоцентрированное обучение» (t4SCL). Студентоцентрированное обучение тесно связано с личностноориентированным подходом, основы которого изложены в трудах известных отечественных ученых-психологов, таких как Б. Г. Ананьев, Л.С. Выготский, А.Н. Леонтьев, С.Л. Рубинштейн, И.А. Зимняя и др. Из чего следует, что "российские ученые еще задолго до Болонского процесса стали рассматривать личность в роли субъекта деятельности, которая сама определяет характер деятельности» (Vaganova, Iliashenko, 2018). В.И. Байденко (Baidenko, 2018) определяет студентоцентрированный подход в обучении «как основной принцип высшего образования, предполагающий активную деятельность обучающихся». При этом «активизация студентов, связанная с достижением конкретного результата, является центральной во всем педагогическом процессе, а его образовательные интересы направлены на формирование профессиональнообразовательных ориентиров» (Vaganova, Prohorova, Karpova, 2019).
Значимую роль в реализации студентоцентрированной направленности обучения современных инженеров играет междисциплинарный подход (Baidenko, 2018; StudentCentred Learning, 2010; Vaganova, Iliashenko, 2018 , etc.). Первыми в отечественной педагогике затронули проблемы интеграции исследователи Г.И. Батурин, С.Я. Баев и Н.Н. Петухов. В системе образования понятие «интеграция» выступает в двух значениях: «1) создание у обучающегося целостного представления об окружающем мире; 2) нахождение общей платформы сближения предметных знаний» (Berulava, 1993). В структуре интеграции значимое место занимают уровни ее реализации. М.Н. Берулава рассматривает три уровня интеграции содержания образования: «1) уровень целостности; 2) уровень дидактического синтеза; 3) уровень межпредметных связей» (Berulava, 1993). Существенная роль в решении вопросов интеграции отводится также выбору ее основ, которые и будут играть системообразующую роль. В.С. Безрукова отмечает, что «определение системообразующего фактора интеграции - это нахождение основания для объединения» (Bezrukova, 1994: 60).

Анализ научно-методической литературы показал наличие множества подходов к осуществлению интеграционных процессов в преподавании математики и информатики как с точки зрения осуществления интеграции непосредственно между этими двумя дисциплинами, так и каждой из этих дисциплин с дисциплинами естественнонаучного цикла. Так, А.Г. Гейн в своем диссертационном исследовании (Gein, 2000) обосновывает, что информационное моделирование выступает в качестве средства реализации межпредметных связей информатики с дисциплинами естественнонаучного профиля, а понятие информационной модели является принципиальным связующим звеном между информатикой и естественнонаучными знаниями. Мнение академика А.П. Ершова: «Информатика, как отдельная наука, вступает в свои права, когда для изучаемого фрагмента мира построена так называемая информационная 
модель ... Информационная модель - это то сопряжение, через которое информатика вступает в отношения с частными науками, не сливаясь с ними и в то же время не вбирая их в себя» (Ershov, 1986: 29-30). Предвосхищая появление цифровой эпохи, А.П. Ершов обозначил требование к цифровым навыкам современного инженера: «Понимание необходимости и способности к построению информационной модели должно стать ... глубинной составляющей инженерно-технического мышления специалиста» (Ershov, 1985: 2).

В научной работе (Dalinger, 2002: 108) обращается внимание на то, что «системообразующим фактором интеграции естественнонаучных и математических дисциплин выступает математическое моделирование, так как оно позволяет интегрировать математические и естественнонаучные знания в процессе построения и исследования математических моделей реальных процессов и явлений». По мнению авторов работ (Dalinger, 2018; Salleh, Zakaria, 2016), преподавание и изучение математики в школах и университетах следует осуществлять с использованием интерактивных средств ИКТ на примере математических сред Maple и MathCAD. А.И. Чучалин, проводя сравнительный анализ компетенций в американской и болонской профессиональных моделях инженера, выделяет «наличие высокого уровня понимания принципов инженерии, основанных на математике и других научных дисциплинах, имеющих отношение к специализации» (Chuchalin, 2007: 88). М. А. Родионов отмечает, что «рассмотрение вопросов преподавания математики в технических вузах целесообразно осуществлять в ракурсе интеграционной модели учебного процесса», что, в свою очередь, актуализирует «потребность в специальном согласовании методологии математики с методологией инженерной деятельности и технических наук» (Rodionov et al., 2018: 383).

Таким образом, опираясь на анализ научных трудов отечественных и зарубежных ученых и анализируя существующие подходы, связанные с вопросами осуществления междисциплинарной интеграции как одно- го из перспективных направлений развития инженерного образования в современном мире, в настоящей работе в качестве системообразующего фактора интеграции знаний по информатике и математике обозначим информационно-математическое моделирование, а в качестве основной проблемы, на решение которой направлено исследование, выявление содержания и методических особенностей включения информационноматематического моделирования в надвигающуюся цифровую образовательную экосистему технического университета. Цель: уход от многопредметности в обучении, лишающей связи между изучаемыми дисциплинами, и переход к межпредметной интеграции, в основу которой положено формирование целостного знания по изучаемым дисциплинам на студентоцентрированной основе.

\section{Материалы и методы}

Теоретические выводы, представленные в данном исследовании, основаны на изучении и анализе научно- и учебнометодической литературы, трудах отечественных и зарубежных ученых в области обучения математике (М. Клайн, А. Н. Колмогоров, Л. Д. Кудрявцев, В. А. Гусев, С.М. Никольский, В.Ф. Бутузов, В.А. Далингер, С.Н. Дворяткина и др.) и информатике (А.Г. Гейн, С.А. Бешенков, А.П. Ершов, К. К. Колин, А. А. Кузнецов, М.П. Лапчик, Н.И. Пак, Е.С. Полат, И. В. Роберт, Е.К. Хеннер и др.). Методологическую основу исследования составили: контекстно-компетентностный (В.И. Байденко, И.А. Зимняя, Дж. Равен, А.В. Хуторской, В.Д. Шадриков, А. А. Вербицкий и др.) и практико-ориентированный подходы к обучению (А.А. Вербицкий, Р. А. Кубанов, И.Ю. Калугина и др.); современные концепции субъектсубъектного взаимодействия: личностноориентированный (А. Г. Асмолов, Б. Г. Ананьев, Л.С. Выготский, А.Н. Леонтьев, С. Л. Рубинштейн, И.А. Зимняя, И. С. Якиманская и др.) и студентоцентрированный подходы (Н.В. Дроздова, М. Ноулз, Г. Райт, К. Роджерс, М. Ханафин, Ф.Х. Хейворд и др.); концепции инновационного под- 
хода CDIO в инженерном образовании (Э.Ф. Кроули, Й. Малмквист, С. Остлунд, Д.Р. Бродер, К. Эдстрем, А.И. Чучалин и др.).

В результате изучения программ и учебно-методических комплексов по дисциплинам (УМКД) математического и информационного циклов проведен подробный анализ существующих межпредметных связей в рамках тем и разделов рассматриваемых дисциплин, на основе которого выдвинута гипотеза о возможных путях осуществления соответствующих интеграционных процессов в обучении студентов инженерных специальностей вузов. При этом, как было обозначено выше, системообразующим фактором интеграции знаний по информатике и математике выступает информационно-математическое моделирование. Выбор форм, средств и методов обучения осуществляется на основе компетентностного, личностно- и практикоориентированного, а также CDIO подходов. Ocобое внимание уделяется организации самостоятельной работы студентов (СРС), способствующей активизации деятельности студента, его мотивации, развитию способности к самообразованию и самоорганизации.

Экспериментальное обучение в рамках поставленной исследовательской задачи, связанной с осуществлением междисциплинарной интеграции математической и информационной подготовки будущих инженеров, основанной на включении в процесс обучения информационно-математического моделирования, предусматривало подготовку студентов к выступлениям с докладами на научных конференциях, публикации научных статей, помощь в выполнении ими выпускных квалификационных работ (ВКР).

Анкетирование студентов первого и второго курсов ФГБОУ ВО «ОмГУПС» в рамках выполнения научноисследовательской работы с целью определения потребностей будущего инженера в области ИКТ позволило в дальнейшем провести анализ основных разделов и соответствующих им тем лабораторных работ в дисциплине «Информатика», в которых целесообразно работать с информационноматематическими моделями (ИММ). Более подробно результаты проведенного опроса и их анализ (табл. 1) представлены в разделе «Результаты исследования и обсуждение» настоящей статьи.

Кроме того, нами был проведен опрос студентов, цель которого заключалась в том, чтобы выяснить, какие именно умения были использованы ими при работе с ИММ. Первый путь подразумевает работу с уже готовыми моделями, исследование которых производится с применением средств ИКТ (например, студенты рассчитывают работу двигателя по его индикаторной диаграмме в ходе проведения опыта, затем берут определенный интеграл, изучают его свойства, физический смысл и приводят его в соответствие с рассматриваемой ситуацией, подобрав соответствующую подынтегральную функцию и произведя расчеты с помощью Excel). Второй вариант связан с тем, что студентам предстоит самостоятельно построить ИММ анализируемой ситуации в задаче, а также исследовать с помощью нее поведение системы в зависимости от изменения рассматриваемых параметров (например, подобную работу можно провести при изучении работы двигателя внутреннего сгорания, в котором трехгранный ротор движется по известной математической кривой - эпитрохоиде. В зависимости от параметров ротора эпитрохоида принимает различные формы. Студенты самостоятельно производят вывод формул для определения координат точек эпитрохоиды, опираясь на результаты опытных данных и знания по геометрии. Применение системы MathCAD во многом облегчает выполнение этой работы, сокращая время ее выполнения и делая соответствующее исследование наглядным. В опросе принимали участие 118 студентов первого и второго курсов ФГБОУ ВО «ОмГУПС» и ФГБОУ ВО «СибАДИ», которые хотя бы раз участвовали в научных конференциях различного уровня, а также выполняли задания исследовательского характера при написании курсовых работ (КР). Результа- 
Viktor A. Dalinger, Natalya A. Moiseeva... Mutual Integration of Information and Mathematical Training for Engineers...

Таблица 1. Перечень разделов и тем, изучаемых в дисциплине «Информатика»

Table 1. The list of sections and topics studied in the discipline «Informatics»

\begin{tabular}{|c|c|c|c|}
\hline $\begin{array}{l}\text { № } \\
\Pi / \Pi\end{array}$ & \multicolumn{2}{|c|}{$\begin{array}{l}\text { Наименование } \\
\text { раздела }\end{array}$} & Наименование темы лабораторной работы \\
\hline \multirow{3}{*}{1} & \multirow{3}{*}{\multicolumn{2}{|c|}{$\begin{array}{c}\text { Теоретические основы } \\
\text { информатики }\end{array}$}} & Системы счисления (B1) \\
\hline & & & $\begin{array}{l}\text { Объемный и вероятностный способы измерения } \\
\text { информации (B2) }\end{array}$ \\
\hline & & & Кодирование информации (B3) \\
\hline \multirow{2}{*}{2} & \multirow{2}{*}{\multicolumn{2}{|c|}{$\begin{array}{c}\text { Архитектура } \\
\text { вычислительных систем }\end{array}$}} & Представление данных в компьютере (D1) \\
\hline & & & Логические основы функционирования ЭВМ (D2) \\
\hline \multirow{13}{*}{3} & \multirow{13}{*}{$\begin{array}{c}\text { Программные } \\
\text { средства } \\
\text { реализации } \\
\text { информационных } \\
\text { процессов }\end{array}$} & \multirow{9}{*}{$\begin{array}{c}\text { Технология } \\
\text { обработки } \\
\text { числовой } \\
\text { информации. } \\
\text { Электронные } \\
\text { таблицы }\end{array}$} & Ввод, редактирование и форматирование данных (Т1) \\
\hline & & & Создание формул. Встроенные функции (Т2) \\
\hline & & & Вычисления с проверкой условия (Т3) \\
\hline & & & $\begin{array}{l}\text { Графики и диаграммы. Графическое решение уравнений } \\
\text { (T4) }\end{array}$ \\
\hline & & & Обработка массивов данных. Макросы (Т5) \\
\hline & & & Обработка списков данных. Защита данных (Т6) \\
\hline & & & $\begin{array}{l}\text { Основы обработки экспериментальных данных в ЭТ } \\
\text { (Т7) }\end{array}$ \\
\hline & & & Подбор параметра. Поиск решения (Т8) \\
\hline & & & Решение оптимизационных задач (Т9) \\
\hline & & \multirow{2}{*}{$\begin{array}{c}\text { Технология } \\
\text { обработки } \\
\text { текстовой } \\
\text { информации }\end{array}$} & $\begin{array}{l}\text { Создание и редактирование графических объектов. } \\
\text { Редактор формул (W1) }\end{array}$ \\
\hline & & & Вычисления в таблицах с помощью формул (W2) \\
\hline & & \multirow{2}{*}{$\begin{array}{c}\text { Технология } \\
\text { баз данных. } \\
\text { Системы } \\
\text { управления } \\
\text { базами данных }\end{array}$} & $\begin{array}{l}\text { Создание вычисляемых запросов к таблице базы данных } \\
\text { (A1) }\end{array}$ \\
\hline & & & Создание отчетов к таблице базы данных (A1) \\
\hline \multirow{9}{*}{4} & \multirow{9}{*}{\multicolumn{2}{|c|}{$\begin{array}{c}\text { Основы алгоритмизации } \\
\text { и программирования }\end{array}$}} & $\begin{array}{l}\text { Линейные вычислительные процессы. Форматный ввод- } \\
\text { вывод данных }\end{array}$ \\
\hline & & & $\begin{array}{l}\text { Разветвляющиеся вычислительные процессы. Простые } \\
\text { и сложные разветвления }\end{array}$ \\
\hline & & & $\begin{array}{l}\text { Разветвляющиеся вычислительные процессы. Выбор } \\
\text { по условию }\end{array}$ \\
\hline & & & \begin{tabular}{llll} 
Циклические & \multicolumn{2}{l}{ вычислительные } & \multicolumn{2}{l}{ процессы. } \\
Арифметический & цикл со счетчиком. \\
с разветвлением & & &
\end{tabular} \\
\hline & & & $\begin{array}{l}\text { Циклические вычислительные } \\
\text { Арифметический цикл со счетчиком. Накопление сумм } \\
\text { и произведений }\end{array}$ \\
\hline & & & $\begin{array}{l}\text { Циклические вычислительные процессы. Итерационные } \\
\text { циклы (циклы с предусловием и постусловием) }\end{array}$ \\
\hline & & & Массивы \\
\hline & & & Подпрограммы (функции и процедуры) \\
\hline & & & $\begin{array}{l}\text { Разработка Windows-приложений средствами языка } \\
\text { объектно-ориентированного программирования }\end{array}$ \\
\hline
\end{tabular}


ты опроса позволили выяснить сформированность следующих умений, необходимых для работы с ИММ при решении задач в профессиональной деятельности:

- самостоятельно осуществлять поиск информации, необходимой для работы с ИММ (76 \%);

- работать с готовой ИММ (62\%);

- строить самостоятельно ИММ рассматриваемой ситуации из профессиональной области (35\%);

- применять средства ИКТ при исследовании ИММ (готовой или построенной самостоятельно) (64 \%);

- интерпретировать результаты построения ИММ согласно рассматриваемой реальной ситуации (45\%).

Исследование показало, что включение в процесс обучения метода информационно-математического моделирования как средства взаимной интеграции подготовки студентов по дисциплинам «Математика» и «Информатика» способствовало пониманию значимости математики, ее идей и методов в будущей профессиональной деятельности студентов, более прочному усвоению знаний не только по указанным дисциплинам, но и по специальным дисциплинам, а также повышению уровня самостоятельности обучаемых в решении проблем и задач, поставленных перед ними. При этом полученные результаты позволили сделать вывод, что на начальном этапе обучения в вузе умения студентов, связанные с работой с ИММ, развиты недостаточно. Например, особую сложность представляли задания, в которых требовалось самостоятельно построить ИММ, а затем правильно интерпретировать результаты работы с ней согласно ситуациям из области профессиональной деятельности студентов. Тогда как сформированность именно этих умений является ключевым вопросом при подготовке ВКР на старших курсах, а также в дальнейшей работе в профессиональной области. В связи с чем встал вопрос поиска оптимального содержания и методических путей включения ИММ в процесс обучения в контексте взаимной интеграции изучаемых дисциплин на уровне не только знаний, но и видов деятельности для получения целостного знания по математическим, информационным и специальным дисциплинам.

\section{Результаты исследования и обсуждение}

В соответствии с основной целью статьи ставится задача выявления особенностей обучения будущих инженеров информационно-математическому моделированию при выполнении СРС в условиях реализации студентоцентрированного обучения. Необходимость работы в направлении организации СРС подтверждается анализом научно- и учебно-методических пособий по выполнению и оформлению рефератов, КР, проектов, производственной практики и других отчетов СРС, ВКР.

Различают два вида СРС:

1. СРС в аудитории: конспектирование лекций; критическая оценка выступления студентов на семинаре, групповых занятиях, конференциях и т. д.

2. СРС вне аудитории: подготовка к аудиторным занятиям; доработка записей по лекционному материалу; проработка учебного материала по другим источникам информации; выполнение домашних заданий, рефератов, расчетно-графических работ, КР, ВКР; подготовка к экзаменам или зачетам; научно-исследовательская работа студента (НИРС) и т. д.

В число основных видов НИРС входят:

1. Учебная НИРС, предусмотренная учебными планами (КР, производственная/ преддипломная практика, ВКР, магистерская диссертация).

2. Исследовательская работа сверх тех требований, которые предъявляются учебными планами (домашние исследовательские задания, лабораторный отчет, реферат, написание научной работы и подготовка доклада для участия в научно-практической конференции (НПК), внутривузовском и национальном конкурсах, научные кружки).

По мнению В.М. Федосеева, НИРС «может быть использована в качестве организационно-методической формы интегрированного обучения. Однако для этого она должна строиться на регулярной 
основе и стать плановым видом учебной работы: с нагрузкой, методическим обеспечением и прочим атрибутом» (Fedoseev, 2016: 131).

В процессе НИРС по фундаментальным естественнонаучным и техническим дисциплинам будущим инженерам часто приходится иметь дело с построением ИММ. Вопросам внедрения методов информационного и математического моделирования в процесс обучения посвящен ряд исследований (Babich, Kremlev, 2016; Chuchalin, 2007; Dalinger, 2002; Dalinger, 2018; Ershov, 1985; Ershov, 1986; Gein, 2000; Monica, 2019; Zagvyazinskiy, 2006, etc.). В построении информационно-математической модели средствами ИКТ и в работе с ней значительную помощь оказывает владение навыками, полученными в результате изучения студентами дисциплины «Информатика». В качестве примера можно привести темы научных работ, выполненных студентами второго и третьего курсов ФГБОУ ВО «ОмГУПС», результаты которых были апробированы в рамках ежегодной Всероссийской студенческой научной конференции, проводимой на базе университета, кафедра «Информатика и компьютерная графика»:

1. «Применение языка программирования Visual Basic for Applications для формирования схем при расчете стержней на растяжение-сжатие».

2. «Синтез логической схемы семисегментного индикатора».

В работе (Moiseeva, 2018) представлены современные средства ИКТ, направленные на оптимальную организацию СРС по информатике и математике и в то же время способствующие трансформации познавательной деятельности современного студента в эпоху цифровизации.

\section{Информационно-математическое моделирование \\ как системообразующий фактор взаимной интеграции знаний по информатике и математике}

Анализ содержания дисциплин, связанных с изучением математического мо- делирования в среде специализированного математического пакета, «позволил выявить следующие разделы математики, задачи из которых рекомендуется решать на лабораторных занятиях по информатике: исследование функций и построение графиков; решение задач по теории вероятностей и математической статистике; построение корреляционных и статистических зависимостей; работа с матрицами; решение систем линейных алгебраических уравнений; вычисление определителей различных порядков и т. д.» (Moiseeva, Poliakova, 2018) (эти темы будут включены в табл. 2).

Вышесказанное можно подкрепить полученными результатами НИРС, выполненной студентом ФГБОУ ВО «ОмГУПС» под руководством одного из авторов настоящей статьи, на предмет исследования потребностей будущего инженера в информационных технологиях. Результаты анкетирования студентов старших курсов ФГБОУ ВО «ОмГУПС» показали, что $96 \%$ среди опрошенных студентов систематически применяют офисный пакет Microsoft Office, $4 \%$ - Open Office, $90 \%$ - математический пакет MathCAD. Наряду с использованием указанных программных средств они также применяют такие специализированные программные средства как LabVIEW и Multisim, выбор которых обусловлен спецификой обучения на соответствующем факультете. Обработка анкетных данных в НИРС осуществлялась с помощью встроенных статистических функций Excel. Отметим, что данная НИРС была представлена на студенческой научной конференции с международным участием «СТУДЕНТ: НАУКА, ПРОФЕССИЯ, ЖИЗНЬ», проводимой на базе ФГБОУ ВО «ОмГУПС», с рекомендацией к публикации в сборнике трудов конференции (Karev, Martyushev, 2018).

Результаты анкетирования, проводимого в рамках описанной выше НИРС (Karev, Martyushev, 2018), а также анализ рабочих учебных программ по подготовке студентов технических вузов по дисциплинам информационно-математического цикла на примере ФГБОУ ВО «ОмГУПС» 
Таблица 2. Матрица наполнения содержания лабораторных работ в разделах «Теоретические основы информатики», «Архитектура вычислительных систем», «Технология обработки числовой информации. Электронные таблицы»

Table 2. The matrix of filling the contents of laboratory work in the section «Theoretical foundations of computer science», «Architecture of computer systems, «Technology of processing numerical information. Spreadsheets»

\begin{tabular}{|c|c|c|c|c|c|c|c|c|c|c|c|c|c|c|}
\hline $\begin{array}{c}\text { Наименование разделов и тем } \\
\text { дисциплины «Математика» }\end{array}$ & B1 & B2 & B3 & D1 & D2 & T1 & $\mathrm{T} 2$ & T3 & $\mathrm{T} 4$ & T5 & T6 & $\mathrm{T} 7$ & $\mathrm{~T} 8$ & T9 \\
\hline $\begin{array}{l}\text { Действия вычислительного характера } \\
\text { с натуральными числами и дробями }\end{array}$ & + & + & + & + & + & + & + & + & & + & + & & & \\
\hline Вычисление логарифмов & & + & + & & & + & + & + & & + & & + & + & \\
\hline Моделирование числовых рядов & & & & + & & + & + & + & & + & + & + & + & \\
\hline Вычисление производной & & & & & & + & + & + & + & & & & & + \\
\hline Вычисление пределов & & & & & & + & + & + & + & & & & & \\
\hline Вычисление определенного интеграла & & & & & & + & + & + & & & & & & \\
\hline Функция. Построение графиков функций & & & & & & + & + & + & + & + & + & + & + & + \\
\hline $\begin{array}{|lrr|}\text { Кривые } & \text { второго } & \text { порядка } \\
\text { и } & \text { пове } & \text { плоскости } \\
\text { в пространстве } & & \text { второго } \\
\end{array}$ & & & & & & + & + & & + & + & & & & \\
\hline Матрицы и действия над ними & & & & & & + & + & + & & + & + & + & & + \\
\hline Решение уравнений с одним неизвестным & & & & & & + & + & + & + & & & & + & \\
\hline $\begin{array}{lll}\text { Системы } & \text { линейных } & \text { алгебраических } \\
\text { уравнений } & \end{array}$ & & & & & & + & + & + & & & & & + & \\
\hline Алгебра высказываний, булевы функции & & & & & + & + & + & + & & + & + & & & \\
\hline $\begin{array}{l}\text { Элементы теории вероятностей } \\
\text { и математической статистики }\end{array}$ & & + & & & & + & + & & + & + & + & + & & \\
\hline Решение задач теории оптимизации & & & & & & + & + & + & & & & & + & + \\
\hline
\end{tabular}

и ФГБОУ ВО «СибАДИ» позволили выделить основные разделы и соответствующие им темы лабораторных работ (табл. 1) в дисциплине «Информатика», в которых задания целесообразно строить на идеях и методах информационно-математического моделирования.

Некоторым темам дисциплины «Информатика» поставлен код (табл. 1), с помощью которого их можно сопоставить с соответствующими темами в математике (табл. 2, 3). Отметим, что поскольку для создания ИММ необходимо написать программу, используя в совокупности конструкции соответствующего языка программирования, то при составлении списка тем лабораторных работ, осваиваемых студентами в разделе «Основы алгоритмизации и программирования», их сопоставление с темами по математике не проводилось. Необходимо отметить, что при выполнении лабораторных работ (табл. 2) требуется привлечение знаний по математике для реализации информационно-математического моделирования.

С позиции реализации вычислений, свойственных математике, функциональные возможности текстового процессора и системы управления базами данных ограничены, поэтому темы (см. табл. 1), связанные с этим ПО, сопоставим с некоторыми темами математики (табл. 3).

Анализ существующих связей в рассмотрении вопросов, изучаемых в дисциплинах информационно-математического цикла, результаты которого отражены в табл. 1-3, а также методических подходов к преподаванию математики и информати- 
Viktor A. Dalinger, Natalya A. Moiseeva... Mutual Integration of Information and Mathematical Training for Engineers...

Таблица 3. Матрица наполнения содержания лабораторных работ в разделах «Технология обработки текстовой информации» и «Технология баз данных. Системы управления базами данных»

Table 3. The matrix of filling the contents of laboratory work in the sections «Technology of processing textual information» and «Technology of databases. Database Management Systems»

\begin{tabular}{|c|c|c|c|c|}
\hline Наименование разделов и тем дисциплины «Математика» & W1 & W2 & A1 & A2 \\
\hline $\begin{array}{l}\text { Создание схем, блок-схем, диаграмм и т. д. для описания математических } \\
\text { понятий, формул и пр. }\end{array}$ & + & & & \\
\hline Визуализация результатов вычислений & + & & & + \\
\hline $\begin{array}{l}\text { Вычислениенесложных формулс использованием базовых математических } \\
\text { и статистических функций }\end{array}$ & & + & + & + \\
\hline
\end{tabular}

ки позволил сформулировать методические рекомендации к организации процесса обучения студентов в рамках осуществления интеграционного подхода при изучении данных дисциплин.

1. Включение в процесс обучения примеров и задач, подразумевающих работу с блок-схемами: чтение блок-схем, самостоятельное их построение. Анализ специальной технической и учебно-методической литературы показал, что блок-схемы широко используются для визуализации технических процессов, алгоритмов функционирования технических устройств и т. д. Кроме того, методические указания по написанию КР и ВКР также содержат требование по использованию блок-схем.

2. В ходе подготовки студента в рамках дисциплин «Информатика» и «Математика» целесообразно предлагать задания для выполнения СРС, в которых используются ИММ.

2.1. Особое внимание необходимо уделять организации НИРС студентов. Следует проводить такие формы НИРС, как реферат и НПК. При этом важно то, что эти дисциплины изучаются на первом курсе и, как следствие этого, прививают будущим инженерам навыки самостоятельной и исследовательской работы с использованием ИММ средствами ИКТ.

2.2. Метод проектов, по мнению ряда специалистов в области методики преподавания различных дисциплин, является одним из эффективных методов организации
$\mathrm{CP}$, реализующим деятельностные основания компетентностного и $\mathrm{CDIO}$ подходов (Yasseri et al., 2018). В этой связи при разработке заданий НИРС для НПК особая роль отводится методу электронных междисциплинарных проектов (Krasavina, Shikhova, 2017), результаты выполнения которых следует оформить в виде доклада и мультимедийной презентации и представить на студенческой НПК.

Главная задача, которая ставится перед инженером в процессе проектирования технического объекта (ТО), - адекватно описать нужный процесс в математических терминах: построить математическую модель и провести ее математический анализ. При этом обработку материала (результаты тестирования модели, экспериментальную часть исследования) можно осуществить с помощью специальных программных средств (компьютера). Это опять же указывает на то, что в процессе математического моделирования важна как математическая подготовка будущего инженера, так и то, насколько глубоко он владеет навыками работы с ИКТ.

Не случайно «математическую основу информатики составляют значимые разделы современной математики, особенно те из них, на которых базируются прикладные разделы математики. В зависимости от этапа решения задачи математические методы, используемые для его поиска, могут быть весьма разнообразны. Например, при постановке задачи речь может идти 
о математическом моделировании, что, в свою очередь, определяет состав входной информации, а также о действиях различного характера, связанных с алгоритмизацией задачи» (Nastashchuk, Poliakova, 2017). Последнее оказывает существенное влияние на выбор математических методов, необходимых как для переработки входной информации, так и для получения требуемых промежуточных или окончательных результатов.

\section{Информационно-математическое моделирование в содержании обучения будущих инженеров}

Анализ содержания табл. 1-3 показывает преобладание в дисциплине «Информатика», прежде всего, тех тем, в которых реализация математических моделей изучается посредством соответствующих программных средств. Математические модели рассматриваются как разновидность информационных моделей в информатике, поэтому эти модели можно назвать «информационно-математическими моделями» (Mogilev et al., 2012).

Математическая модель - информационная модель, построенная с использованием математических понятий и формул.

Математическая модель технического объекта - совокупность математических объектов и отношений между ними, которые верно отражают свойства разрабатываемого устройства.

Академик А.А. Самарский считается основоположником отечественного математического моделирования. Именно он выразил методологию математического моделирования знаменитой триадой «модель - алгоритм - программа» (Samarskii, Mikhailov, 2005).

I этап. Модель. Выбирается или создается модель исследуемого ТО, отражающая его значимые свойства в математической форме.

II этап. Алгоритм. Выбирается или разрабатывается алгоритм для реализации построенной модели на компьютере. Проводится изучение построенной ИММ методами вычислительной математики.
III этап. Программа. Создается компьютерная программа для реализации ИММ и алгоритма на компьютере.

Предложенная методология получила свое развитие в виде технологии «вычислительного эксперимента». В настоящее время принято говорить о компьютерном математическом моделировании, или компьютерной (информационно-) математической модели (KMM), под которой будем понимать программу, которая исполняет расчеты состояния моделируемой системы по ее ИММ (Samarskii, Mikhailov, 2005).

КММ реализуются с помощью средств систем программирования, технологии ЭТ, математических пакетов и другого специализированного ПО для моделирования. Необходимо отметить, что важным свойством КММ является возможность визуализации результатов расчетов с помощью средств компьютерной графики (анимация, блок-схема, диаграммы, схемы, чертежи и др.).

Аналитический обзор специализированной литературы (Mogilev et al., 2012; Samarskii, 2005; Sovetov, Sovetov, 2017; etc.) позволил выявить методы реализации ИММ на компьютере (табл. 4): графические (Гр), аналитические (Ан), вероятностностатистические (ВС), имитационные (Им), численные (Чс) методы. Эти методы можно использовать как самостоятельно, так и комплексно.

В табл. 5 представлено ПО, функциональные возможности которого позволяют реализовать рассмотренные выше методы (см. табл. 4).

Для системного описания большого разнообразия ИММ, используемых специалистами инженерного профиля, требуется их классификация. Анализ работ авторов, занимающихся вопросами математического и информационно-математического моделирования (Dalinger, 2018; Khekalo, 2015; Mogilev, 2012; Samarskii, Mikhailov, 2005; Sovetov, 2017, etc.), позволил объединить существующие подходы к классификации математических моделей, применяемых в задачах по информатике для будущих инженеров (табл. 6). 
Таблица 4. Методы реализации ИММ

Table 4. Methods for implementing IMM

\begin{tabular}{|c|c|c|}
\hline $\begin{array}{c}\text { Наименование } \\
\text { метода }\end{array}$ & Назначение ИММ & Краткая характеристика метода \\
\hline Графические & $\begin{array}{l}\text { Оценивают порядок входных параметров } \\
\text { ИММ и направление исполнения расчетных } \\
\text { алгоритмов }\end{array}$ & \begin{tabular}{|lll} 
Представляют & ТО & в \\
технологических & карт, & диаграмм, \\
блок-схемы и т. д. & & \\
\end{tabular} \\
\hline Аналитические & $\begin{array}{l}\text { Выражают неизвестные величины через } \\
\text { входные параметры в явном функциональном } \\
\text { виде: } y_{j}=F_{j}\left(x_{1}, x_{2}, \ldots, x_{n}\right),(j=1,2, \ldots, k) \text {. } \\
\text { По данным формулам выполняются любые } \\
\text { вычисления для нужных значений входных } \\
\text { параметров }\end{array}$ & $\begin{array}{l}\text { Реализуются в специализированных } \\
\text { математических пакетах, в которых } \\
\text { ИММ представляет собой систему } \\
\text { уравнений, при решении которой } \\
\text { получают параметры для оценки ТО }\end{array}$ \\
\hline $\begin{array}{l}\text { Вероятностно- } \\
\text { статистические }\end{array}$ & $\begin{array}{l}\text { Устанавливают зависимости между } \\
\text { выходными характеристиками ТО и его } \\
\text { входными параметрами, в случае если эти } \\
\text { зависимости стохастичны по своей природе } \\
\text { и выявляются на основании выборочных } \\
\text { данных статистического наблюдения } \\
\text { за анализируемыми переменными }\end{array}$ & $\begin{array}{l}\text { Используются при обработке } \\
\text { результатов, полученных имитацион- } \\
\text { ными методами }\end{array}$ \\
\hline Имитационные & $\begin{array}{l}\text { Анализ ТО, в котором стохастические } \\
\text { воздействия преобладают }\end{array}$ & $\begin{array}{l}\text { Визуализируют реальные процессы } \\
\text { и ситуации, характерные для ТО }\end{array}$ \\
\hline Численные & $\begin{array}{l}\text { Используются в том случае, когда не удается } \\
\text { получить аналитическое решение для ИММ }\end{array}$ & $\begin{array}{l}\text { Реализуются } \\
\text { вычислительной } \\
\text { в которых ИММ представляет собой } \\
\text { систему линейных и нелинейных } \\
\text { уравнений }\end{array}$ \\
\hline
\end{tabular}

Таблица 5. ПО для методов реализации ИММ

Table 5. Software for methods of implementing IMM

\begin{tabular}{|c|c|c|c|c|c|c|c|}
\hline \multirow{2}{*}{$\begin{array}{l}\text { № } \\
\Pi / \Pi\end{array}$} & \multicolumn{2}{|r|}{ Наименование ПО } & \multicolumn{5}{|c|}{ Методы } \\
\hline & Группа & Вид & $\Gamma \mathrm{p}$ & $\mathrm{Aн}$ & $\mathrm{BC}$ & Им & Чс \\
\hline \multirow{3}{*}{1} & \multirow{3}{*}{$\begin{array}{l}\text { Прикладное ПО } \\
\text { общего назначения }\end{array}$} & $\begin{array}{l}\text { Электронные таблицы (Microsoft Excel, } \\
\text { QuattroPro OpenOffice.Org Calc, и др.) }\end{array}$ & + & + & + & + & + \\
\hline & & $\begin{array}{l}\text { Текстовый процессор (Microsoft Word, } \\
\text { OpenOffice.org Writer и др.) } \\
\end{array}$ & + & $+/-$ & $+/-$ & & \\
\hline & & $\begin{array}{l}\text { Системы управления базами данных (Mic- } \\
\text { rosoft Access, Informix, Oracle и др.) }\end{array}$ & & $+/-$ & $+/-$ & & \\
\hline \multirow{3}{*}{2} & \multirow{3}{*}{$\begin{array}{l}\text { Специализирован- } \\
\text { ное прикладное ПО }\end{array}$} & $\begin{array}{l}\text { Математические пакеты (MathLab, Math- } \\
\text { Cad, Maple, «Математика» и др.) }\end{array}$ & + & + & + & & + \\
\hline & & $\begin{array}{l}\text { Программныесредствадля имитационного } \\
\text { моделирования (Arena, AveSim, Any-Logic, } \\
\text { GPSS, Simula и др.) }\end{array}$ & & & & + & + \\
\hline & & $\begin{array}{l}\text { Программные средства статистической } \\
\text { обработки данных (Statistica, SPSS, Stat- } \\
\text { Graphs и др.) }\end{array}$ & + & & + & + & \\
\hline 3 & \multicolumn{2}{|c|}{$\begin{array}{l}\text { Системы программирования (Embarcadero C++ Builder, Mic- } \\
\text { rosoft Visual Basic, Microsoft Visual C++, Fortran и др.) }\end{array}$} & + & + & + & + & + \\
\hline
\end{tabular}

«+» - функциональные возможности ПО реализуют метод в полном объеме. «+/» - функциональные возможности ПО частично реализуют метод. 
Таблица 6. Классификация ИММ

Table 6. IMM classification

\begin{tabular}{|c|c|c|c|}
\hline $\begin{array}{c}\text { № } \\
\Pi / \Pi\end{array}$ & \multicolumn{2}{|c|}{ Признак классификации } & Типы ИММ \\
\hline \multirow{5}{*}{1} & \multirow{5}{*}{\multicolumn{2}{|c|}{ По цели моделирования ТО }} & Дескриптивные (описательные) \\
\hline & & & Кибернетические (игровые) \\
\hline & & & Имитационные \\
\hline & & & Оптимизационные однокритериальные \\
\hline & & & Оптимизационные многокритериальные \\
\hline \multirow{9}{*}{2} & \multirow{9}{*}{$\begin{array}{c}\text { По характеру } \\
\text { процессов, } \\
\text { протекающих } \\
\text { в ТО }\end{array}$} & \multirow{4}{*}{$\begin{array}{c}\text { Наличие } \\
\text { неизвестных } \\
\text { факторов }\end{array}$} & Детерминированные \\
\hline & & & Стохастические (вероятностные) \\
\hline & & & Нечеткие \\
\hline & & & Комбинированные \\
\hline & & \multirow{2}{*}{$\begin{array}{c}\text { Наличие } \\
\text { временных } \\
\text { факторов }\end{array}$} & Статические \\
\hline & & & Динамические \\
\hline & & \multirow{3}{*}{$\begin{array}{c}\text { По области } \\
\text { определения } \\
\text { независимых } \\
\text { переменных }\end{array}$} & Дискретные \\
\hline & & & Непрерывные \\
\hline & & & Дискретно-непрерывные \\
\hline \multirow{3}{*}{3} & \multirow{3}{*}{\multicolumn{2}{|c|}{$\begin{array}{c}\text { По принадлежности } \\
\text { к иерархическому уровню } \\
\text { описания ТО }\end{array}$}} & Модель микроуровня \\
\hline & & & Модель макроуровня \\
\hline & & & Модель метауровня \\
\hline \multirow{3}{*}{4} & \multirow{3}{*}{\multicolumn{2}{|c|}{$\begin{array}{c}\text { По способу представления } \\
\text { свойств ТО }\end{array}$}} & Алгоритмические \\
\hline & & & Аналитические \\
\hline & & & Имитационные \\
\hline \multirow{3}{*}{5} & \multirow{3}{*}{\multicolumn{2}{|c|}{$\begin{array}{c}\text { По характеру отображаемых } \\
\text { свойств ТО }\end{array}$}} & Структурные \\
\hline & & & Функциональные \\
\hline & & & Функционально-логические \\
\hline \multirow{3}{*}{6} & \multirow{3}{*}{\multicolumn{2}{|c|}{$\begin{array}{c}\text { По способу получения } \\
\text { функциональных } \\
\text { зависимостей ТО }\end{array}$}} & Теоретические \\
\hline & & & Формальные \\
\hline & & & Эмпирические \\
\hline
\end{tabular}

С точки зрения применения ИММ к описанию свойств и процессов, характерных для ТО, эти модели проектируются и обрабатываются в большей степени инструментарием специализированного прикладного ПО, которое используется в научной и практической деятельности инженера.

Опираясь на представленную классификацию ИММ (см. табл. 6) и темы, изучаемые будущими инженерами в вузовском курсе информатики (см. табл. 1-3), составим матрицу, которая наглядно отразит его потенциал для создания ИММ (табл. 7).

Содержание табл. 7 показывает, что на первом курсе не все ИММ возможно реализовать при изучении тем вузовского курса «Информатика» и, соответственно, организации СР студентов. Рекомендуется формулировать ИУЗ, решение которых основано на построении, реализации и исследовании обозначенных ИММ (табл. 7). Типология ИУЗ по информатике и матема- 
Таблица 7. Матрица возможной реализации ИММ в вузовском курсе «Информатика» Table 7. The matrix of the possible implementation of IMM in the university course «Informatics»

\begin{tabular}{|c|c|c|c|c|c|c|c|c|c|c|c|c|c|c|c|}
\hline \multirow{2}{*}{$\begin{array}{l}\text { № } \\
\Pi / \Pi\end{array}$} & \multirow{2}{*}{ Типы ИММ } & \multicolumn{14}{|c|}{ Темы, изучаемые в вузовском курсе Информатика» } \\
\hline & & $\mathrm{T} 1$ & $\mathrm{~T} 2$ & T3 & T4 & T5 & T6 & T7 & T8 & T9 & $\mathrm{P}$ & A1 & A2 & W1 & W2 \\
\hline 1. & Дескриптивные & + & + & + & + & & & + & & & + & + & + & + & + \\
\hline 2. & Кибернетические & + & + & + & + & + & + & + & + & + & + & & & & + \\
\hline 3. & Имитационные & + & + & + & + & + & & + & & & + & + & + & + & + \\
\hline 4. & $\begin{array}{c}\text { Оптимизационные } \\
\text { однокритериальные }\end{array}$ & + & & + & + & + & + & & & + & + & & & & + \\
\hline 5. & $\begin{array}{c}\text { Оптимизационные } \\
\text { многокритериальные }\end{array}$ & + & + & + & + & + & + & + & + & + & + & + & + & + & + \\
\hline 6. & Детерминированные & + & + & + & + & & + & & + & & + & + & + & & + \\
\hline 7. & Стохастические & + & + & + & & + & + & + & + & & + & + & + & + & + \\
\hline 8. & Нечеткие & + & & & + & + & & & + & & + & & & & + \\
\hline 9. & Комбинированные & + & + & + & + & + & + & + & + & + & + & + & + & + & + \\
\hline 10. & Статические & + & + & + & + & & & & & & + & & & & + \\
\hline 11. & Динамические & + & + & + & + & + & + & + & + & + & + & + & + & + & + \\
\hline 12 & Дискретные & + & + & & & & + & & + & & + & & & & + \\
\hline 13. & Непрерывные & + & + & + & + & + & + & + & & + & + & + & + & + & + \\
\hline 14. & Дискретно-непрерывные & + & + & + & + & & + & & & + & + & + & + & + & + \\
\hline 15. & Модель микроуровня & + & + & + & & + & & + & & & + & & & + & + \\
\hline 16. & Модель макроуровня & + & + & + & & + & & & & & + & & + & & + \\
\hline 17. & Модель метауровня & + & + & + & & + & & + & & & + & & & + & + \\
\hline 18. & Алгоритмические & + & + & + & & + & & & & & + & & + & & + \\
\hline 19. & Аналитические & + & + & + & + & + & + & + & + & + & + & + & + & + & + \\
\hline 20. & Имитационные & + & + & + & + & & + & + & + & + & + & + & + & + & + \\
\hline 21. & Структурные & + & + & + & & + & + & & & & + & & & + & + \\
\hline 22. & Функциональные & + & + & + & + & + & + & + & + & + & + & + & + & + & + \\
\hline 23. & $\begin{array}{c}\text { Функционально- } \\
\text { логические }\end{array}$ & + & + & + & + & + & + & + & + & + & + & + & + & + & + \\
\hline 24. & Теоретические & + & + & + & & + & + & + & & + & + & + & + & + & + \\
\hline 25. & Формальные & + & + & + & & + & + & & & & + & & & + & + \\
\hline 26. & Эмпирические & + & + & + & + & + & + & + & + & + & + & + & + & + & + \\
\hline
\end{tabular}

тике для будущих инженеров представлена в работе (Dalinger et al., 2020).

\section{Схема непрерывной интеграции информационно-математической подготовки будущих инженеров}

Анализ ООП и учебных планов подготовки будущих инженеров показал, что дисциплины, в которых изучается математическое моделирование ТО с помощью специ- ализированного ПО, как правило, начинают преподавать студентам на втором курсе (см. табл. 5). Затем студенты продолжают осваивать специальные дисциплины, изучают ИКТ или/и автоматизированные информационные системы в соответствующей отрасли производства, для которой осуществляется подготовка будущих инженеров. В рамках этих дисциплин студенты строят ИММ с помощью средств математического обеспече- 
ния специализированной ИКТ или/и автоматизированной информационной системы. Таким образом, при обучении будущего инженера в техническом вузе его готовят к непрерывному образованию, в том числе в области информационно-математического моделирования.

На основе анализа содержания табл. 7, форм внеаудиторной СРС определим возможную схему реализации ИММ в СР будущего инженера в процессе всей подго- товки в техническом вузе (табл. 8). Введем следующие обозначения внеаудиторной СРС, в которых целесообразно исследовать $\mathrm{TO}$, особенности его функционирования и поведения посредством ИММ, реализованной на компьютере:

$\mathrm{CP}^{и}$ - СРС по дисциплине «Информатика»;

$\mathrm{CP}^{\mathrm{M}}$ - СРС по дисциплине «Математика»; $\mathrm{CP}^{\mathrm{MM}}$ - СРС по дисциплине, в которой изучается математическое моделирование ТО;

Таблица 8. Реализация ИММ в самостоятельной работе будущего инженера при обучении в техническом вузе

Table 8. IMM implementation in the future engineer's independent work while studying at a technical university

\begin{tabular}{|c|c|c|c|c|c|c|c|}
\hline \multirow{2}{*}{$\begin{array}{l}\text { № } \\
\Pi / \Pi\end{array}$} & \multirow{2}{*}{$\begin{array}{l}\text { Курс, семестр } \\
\text { Тип ИММ }\end{array}$} & 1 & 2 & 3 & $4 / 4^{\mathrm{5}}$ & $5 / 5^{\mathrm{C}}$ & $6^{\mathrm{M}}$ \\
\hline & & $1-2$ & $3-4$ & $5-6$ & $7-8$ & $9-10$ & $11-12$ \\
\hline 1 & 2 & 3 & 4 & 5 & 6 & 7 & 8 \\
\hline \multirow{2}{*}{1.} & \multirow{2}{*}{ Дескриптивные } & $\mathrm{CP}^{\mathrm{U}}, \mathrm{CP}^{\mathrm{M}}$ & $\mathrm{CP}^{\mathrm{MM}}$ & $\mathrm{CP}^{\text {СД}, ~ П ~}$ & СРС,$\Pi$ & СРС, П & \\
\hline & & НИРС $^{\text {И }}$, НИРС $^{\mathrm{M}}$ & НИРС, КР & НИРС, КР & КР, ВКР & $\mathrm{KP}, \mathrm{BKP}^{\mathrm{C}}$ & КР, ВКР \\
\hline 1 & 2 & 3 & 4 & 5 & 6 & 7 & 8 \\
\hline \multirow{2}{*}{2.} & \multirow{2}{*}{ Кибернетические } & $\mathrm{CP}^{\mathrm{U}}, \mathrm{CP}^{\mathrm{M}}$ & $\mathrm{CP}^{\mathrm{MM}}$ & $\mathrm{CP}^{\text {СД }, ~ П ~}$ & СРСД, П & СРСД, П & \\
\hline & & НИРС $^{\text {и }}$, НИРС $^{\mathrm{M}}$ & НИРС, КР & НИРС, КР & КР, ВКР & $\mathrm{KP}, \mathrm{BKP} \mathrm{P}^{\mathrm{C}}$ & КР, ВКР \\
\hline \multirow{2}{*}{3.} & \multirow{2}{*}{ Имитационные } & $\mathrm{CP}^{\mathrm{U}}, \mathrm{CP}^{\mathrm{M}}$ & $\mathrm{CP}^{\mathrm{MM}}$ & $\mathrm{CP}^{\text {СД }}, \Pi$ & СРС,$\Pi$ & СРсд, П & \\
\hline & & НИРС $^{\text {И }}$, НИРС $^{\mathrm{M}}$ & НИРС, КР & НИРС, КР & КР, BKР & $\mathrm{KP}, \mathrm{BKP}^{\mathrm{C}}$ & КР, BКР ${ }^{\mathrm{M}}$ \\
\hline \multirow{2}{*}{4.} & \multirow{2}{*}{$\begin{array}{c}\text { Оптимизационные } \\
\text { однокритериальные }\end{array}$} & $\mathrm{CP}^{\mathrm{U}}, \mathrm{CP}^{\mathrm{M}}$ & $\mathrm{CP}^{\mathrm{MM}}$ & $\mathrm{CP}^{\text {СД }}$ & & & \\
\hline & & НИРС $^{\text {и }}$, НИРС $^{\mathrm{M}}$ & НИРС, КР & НИРС, КР & & & КР, ВКР ${ }^{\mathrm{M}}$ \\
\hline \multirow{2}{*}{5.} & \multirow{2}{*}{$\begin{array}{c}\text { Оптимизационные } \\
\text { многокритериальные }\end{array}$} & $\mathrm{CP}^{\mathrm{u}}, \mathrm{CP}^{\mathrm{M}}$ & $\mathrm{CP}^{\mathrm{MM}}$ & СРСД & СРСД, П & СРСД, П & \\
\hline & & НИРС $^{\text {И }}$, НИРС $^{\mathrm{M}}$ & НИРС, КР & НИРС, КР & КР, ВКР & $\mathrm{KP}, \mathrm{BKP}^{\mathrm{C}}$ & КР, ВК ${ }^{\mathrm{M}}$ \\
\hline \multirow{2}{*}{6.} & \multirow{2}{*}{ Детерминированные } & $\mathrm{CP}^{\mathrm{U}}, \mathrm{CP}^{\mathrm{M}}$ & $\mathrm{CP}^{\mathrm{MM}}$ & $\mathrm{CP}^{\text {СД }}$ & $\mathrm{CP}^{\text {Сд }}, \Pi$ & $\mathrm{CP}^{\text {Сд }}, \Pi$ & \\
\hline & & НИРС $^{\text {И }}$, НИРС $^{\mathrm{M}}$ & НИРС, КР & & КР, ВКР & $\mathrm{KP}, \mathrm{BKP}^{\mathrm{C}}$ & $\mathrm{BKP}^{\mathrm{M}}$ \\
\hline \multirow{2}{*}{7.} & \multirow{2}{*}{ Стохастические } & $\mathrm{CP}^{\mathrm{U}}, \mathrm{CP}^{\mathrm{M}}$ & $\mathrm{CP}^{\mathrm{MM}}$ & $\mathrm{CP}^{\text {СД }}, \Pi$ & СРСД, П & СРСД, П & $\mathrm{HИРС}^{\mathrm{M}}$ \\
\hline & & НИРС $^{\text {и }}$, НИРС $^{\mathrm{M}}$ & НИРС, КР & НИРС, КР & КР, ВКР & $\mathrm{KP}, \mathrm{BKP}^{\mathrm{C}}$ & $\mathrm{BKP}^{\mathrm{M}}$ \\
\hline \multirow{2}{*}{8.} & \multirow{2}{*}{ Нечеткие } & $\mathrm{CP}^{\mathrm{U}}, \mathrm{CP}^{\mathrm{M}}$ & $\mathrm{CP}^{\mathrm{MM}}$ & $\mathrm{CP}^{\text {СД }}, \Pi$ & $\mathrm{CP}^{\text {СД }}, \Pi$ & $\mathrm{CP}^{\text {С }}, \Pi$ & $\mathrm{BKP}^{\mathrm{M}}$ \\
\hline & & НИРС $^{И}$, НИРС $^{\mathrm{M}}$ & НИРС, КР & НИРС, КР & КР, ВКР & $\mathrm{KP}, \mathrm{BKP}^{\mathrm{C}}$ & НИРС $^{\mathrm{M}}$ \\
\hline \multirow{2}{*}{9.} & \multirow{2}{*}{ Комбинированные } & $\mathrm{CP}^{\mathrm{U}}, \mathrm{CP}^{\mathrm{M}}$ & $\mathrm{CP}^{\mathrm{MM}}$ & $\mathrm{CP}^{\text {СД }}, \Pi$ & $\mathrm{CP}^{\text {С }}, \Pi$ & СРСД, П & $\mathrm{BKP}^{\mathrm{M}}$ \\
\hline & & 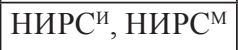 & НИРС, КР & НИРС, КР & КР, ВКР & $\mathrm{KP}, \mathrm{BKP} \mathrm{P}^{\mathrm{C}}$ & НИРС $^{\mathrm{M}}$ \\
\hline \multirow{2}{*}{10.} & \multirow{2}{*}{ Статические } & $\mathrm{CP}^{\mathrm{U}}, \mathrm{CP}^{\mathrm{M}}$ & $\mathrm{CP}^{\mathrm{MM}}$ & СРСД, П & СРСД, П & СРСД, П & $\mathrm{BKP}^{\mathrm{M}}$ \\
\hline & & НИРС $^{\text {И }}$, НИРС $^{\mathrm{M}}$ & НИРС, КР & НИРС, КР & КР, BKP & $\mathrm{KP}, \mathrm{BKP}^{\mathrm{C}}$ & \\
\hline \multirow{2}{*}{11.} & \multirow{2}{*}{ Динамические } & $\mathrm{CP}^{\mathrm{U}}, \mathrm{CP}^{\mathrm{M}}$ & $\mathrm{CP}^{\mathrm{MM}}$ & $\mathrm{CP}^{\text {СД }}, \Pi$ & $\mathrm{CP}^{\mathrm{CД}}, \Pi$ & $\mathrm{CP}^{\mathrm{CД}}, \Pi$ & $\mathrm{BKP}^{\mathrm{M}}$ \\
\hline & & НИРС $^{\text {И }}$, НИРС $^{\mathrm{M}}$ & НИРС, КР & НИРС, КР & КР, ВКРБ & $\mathrm{KP}, \mathrm{BKP}^{\mathrm{C}}$ & НИРС $^{\mathrm{M}}$ \\
\hline \multirow{2}{*}{12.} & \multirow{2}{*}{ Дискретные } & $\mathrm{CP}^{и}, \mathrm{CP}^{\mathrm{M}}$ & $\mathrm{CP}^{\mathrm{MM}}$ & $\mathrm{CP}^{\text {СД }}, \Pi$ & СРСД, П & СРСД, П & $\mathrm{BKP}^{\mathrm{M}}$ \\
\hline & & НИРС $^{и}$, НИРС $^{\mathrm{M}}$ & НИРС, КР & НИРС, КР & КР, BKР & $\mathrm{KP}, \mathrm{BKP}^{\mathrm{C}}$ & \\
\hline
\end{tabular}


СРСД - СРС по дисциплине, где изучаются ИКТ или/и автоматизированные информационные системы в соответствующей отрасли, для которой осуществляется подготовка будущих инженеров;

НИРС ${ }^{и}$ - НИРС по дисциплине «Информатика» (реферат, НПК);

НИРС $^{\mathrm{M}}$ - НИРС по дисциплине «Математика» (реферат, НПК);

КР - курсовая работа;

П - производственная, преддипломная практика;

ВКРБ - ВКР инженера-бакалавра;

$\mathrm{BK}^{\mathrm{M}}$ - магистерская диссертация;

$\mathrm{BKP}^{\mathrm{C}}$ - ВКР инженера-специалиста;

$4^{\text {Б }}$ - четвертый курс обучения инженера-бакалавра;

$5^{\mathrm{C}}$ - пятый курс обучения инженераспециалиста;

$6^{\mathrm{M}}$ - шестой курс обучения инженерамагистра.

\section{Заключение}

Проведенный анализ актуальных подходов к осуществлению взаимной интеграции информационно-математической подготовки в рамках настоящего исследования позволил сформулировать следующие выводы.

1. Показана значимость информационно-математической подготовки в условиях реализации стандартов нового поколения инженерного профиля. Обозначено, что информационно-математическое моделирование выступает системообразующим фактором взаимной интеграции, так как оно позволяет интегрировать знания по информатике и математике в процессе построения и исследования ИММ ТО. При этом определен потенциал информационноматематического моделирования для ИУЗ, являющихся основой технологии взаимной интеграции дисциплин «Информатика» и «Математика».

2. Предложена классификация ИММ ТО и систематизировано ПО для реализации методов ИММ, которые служат основой отбора учебного и специализированного материала при формировании системы ИУЗ, ориентированных на практическое применение полученных знаний будущим инженером, что соответствует студентоцентрированной направленности обучения в рамках идеологии компетентностного подхода.

3. Определена одна из наиболее эффективных организационных форм взаимной интеграции информатики и математики - СРС - в период обучения студента в экосистеме технического вуза. Представлены методические аспекты интеграции информационно-математической подготовки, реализуемые посредством использования в обучении интерактивных, контекстных и проектных технологий. Предложена схема реализации ИММ в СРС при обучении в экосистеме технического университета.

Таким образом, проведенное исследование показало необходимость усовершенствования студентоцентрированной направленности обучения будущих инженеров в условиях прогрессирующей цифровизации экономики и общества. Дальнейшие перспективы исследования заключаются в продолжении разработки проблемы интеграции информатики и математики на уровне дидактического синтеза в эпоху становления и развития методологии цифровизации образовательного процесса, а также масштабных и ускоряющихся технологических изменений в мире.

\section{Список литературы / References}

Auer, M., Dobrovska, D., Edwards, A., Likl, E. (2013). Perspektivy razvitiia inzhenernogo obrazovaniia s pozicii IGIP [Prospects for the development of engineering education from the perspective of IGIP]. In Vysshee obrazovanie v Rossii [Higher Education in Russia], 2, 39-45.

Auer, M.A. (2014). Mezhdunarodnoe obshchestvo po inzhenernoi pedagogike (IGIP) i novye vyzovy v inzhenernom obrazovanii [International Society for Engineering Education (IGIP) and new challenges in engineering education]. In Vysshee obrazovanie v Rossii [Higher Education in Russia], $6,28-33$. 
Babich, V.N., Kremlev, A.G. (2016). Informatsionno-matematicheskoe modelirovanie ob»ektov arhitektury [Information-mathematical modeling of architecture objects]. In Sbornik materialof Vserossijskoi nauchnoi konferencii s Mezhdunarodnym uchastiem «Teoriya sovremennogo goroda: proshloe, nastoyashchee, budushchee» [Materials of the All-Russian scientific conference with international participation «Theory of the modern city: Past, Present, Future»]. Ekaterinburg, 45-47.

Baidenko, V.I. (2018). Bolonskii process: v preddverii tret'ego desiatiletiia [Bologna process: on the eve of the third decade]. In Vysshee obrazovanie v Rossii [Higher Education in Russia], 27(11), 136-148. DOI: 10.31992/0869-3617-2018-27-11-136-148

Berulava, M.N. (1993). Integraciya soderzhaniya obrazovaniya [Integration of educational content]. Moscow, Pedagogika, $172 \mathrm{p}$.

Bezrukova, V.S. (1994). Integracionny'e processy v pedagogicheskoi teorii i praktike [Integration processes in pedagogical theory and practice]. Ekaterinburg, $152 \mathrm{p}$.

Chuchalin, A.I. (2007). Amerikanskaia i bolonskaia modeli inzhenera: sravnitel'nyj analiz kompetentsii [American and Bologna models of engineer: a comparative analysis of competences]. In Voprosy obrazovaniya [Educational Studies Moscow], 1, 84-93, available at: https://vo.hse.ru/data/2010/12/31/1208183718/ p84.pdf (accessed 18 April 2019)

Chuchalin, A.I. (2018). Modernizatsiia trehurovnevogo inzhenernogo obrazovaniia na osnove FGOS3++ i CDIO++ [Modernization of three-level engineering education based on GEF $3++$ and $\mathrm{CDIO}++]$. In Vysshee obrazovanie v Rossii [Higher Education in Russia], 4, 22-32.

Dalinger, V.A. (2002). Matematicheskoe modelirovanie kak sredstvo integratsii estest-venno-nauchnyh i matematicheskih distsiplin [Mathematical modeling as a means of integration of natural science and mathematical disciplines]. In Integratsiya obrazovaniya [Integration of Education], 4, 106-112. Available at: http://edumag.mrsu.ru/content/pdf/02-4.pdf (accessed 17 May 2019)

Dalinger, V.A. (2018). Obuchenie uchashchihsia resheniiu ekonomicheskih zadach v matematicheskih sredah MATHCAD i MAPLE [Training of students to solve the economic tasks in MATHCAD and MAPLE]. In Sovremennye problemy nauki i obrazovaniya [Modern problems of science and education], 2, 108, available at: http://science-education.ru/ru/article/view?id=27529 (accessed 11 July 2019)

Dalinger, V.A., Moiseeva, N.A., Polyakova, T.A. (2020). Information and mathematical modeling as the basis for the professional activity of future engineers in the digitization era. In Advances in Social Science, Education and Humanities Research. Proceedings of the International Scientific Conference «Digitalization of Education: History, Trends and Prospects» (DETP 2020), France, Atlantis Press, 593-598. DOI: https://doi.org/10.2991/assehr.k.200509.108

Dolzhenko, R.A. (2017). Kontseptsiia CDIO kak osnova inzhenernogo obrazovaniia: promezhutochnye itogi i napravleniia dal'nejshego ispol'zovaniia $\mathrm{v}$ Rossii [CDIO concept as a basis of engineering education: intermediate results and directions of further use in Russia]. In Izvestiya Uralskogo gosudarstvennogo gornogo universiteta [News of the Ural State Mining University], 2 (46), 104-108. Available at: https://cyberleninka.ru/article/n/kontseptsiya-cdio-kak-osnova-inzhenernogo-obrazovaniya-promezhutochnye-itogi-inapravleniya-dalneyshego-ispolzovaniya-v-rossii (accessed 12 June 2019)

Drozdova, N.V., Lobanov, A.P. (2007). Kompetentnostnyj podhod kak novaya paradigma studentocentrirovannogo obrazovaniya [Competence approach as a new paradigm of student-centered education]. Minsk, RIVSH, $100 \mathrm{p}$.

Education for a complex society. «Educational Ecosystems for Social Transformation» (2018). In Doklad Global Education Futures, available at: https://drive.google.com/file/d/0B9ZvF6mQ5FMbSTFKVmhodU5rNTNiTXpUZ2QwZktiR0pzSmJR/view (accessed 8 May 2020)

Ershov, A.P. (1985). Ob informatsionnoi modeli mashiny [On the information model of the machine]. In Mikroprocessornye sredstva i sistemy [Microprocessor based tools and systems], 4.

Ershov, A.P. (1986). Informatika: predmet i poniatie [Computer science: subject and concept]. In Kibernetika. Stanovlenie informatiki [Cybernetics. The formation of computer science], Moscow, Nauka, 3-34.

Fedoseev, V.M. (2016). Nauchno-issledovatel'skaia rabota so studentami kak forma integracii inzhenernoi i matematicheskoi podgotovki v uchebnom processe vuza [Research work with students as 
a form of integration of engineering and mathematical training in the educational process of the University]. In Integraciya obrazovaniya [Integration of Education], 20 (1), 125-133. DOI: 10.15507/19919468.082.020.201601.125-133

Gein, A.G. (2000). Izuchenie informatsionnogo modelirovaniia kak sredstvo realizatsii mezhpredmetnyh sviazei informatiki s distsiplinami estestvennonauchnogo tsikla. Dissertatsiia doktora pedagogicheskih nauk [The study of information modeling as a means of implementing intersubject communications of computer science with the disciplines of the natural science cycle. The dissertation of Doctors of pedagogical sciences].

Hannafin, M.J., Hannafin, K.M. (2010). Cognition and student centered, web-based learning: Issues and implications for research and theory. In Learning and instruction in the digital age. Springer US, 11-23.

Karev, N.S., Martyushev, S.A. (2018). Issledovanie informatsionnyh potrebnostei budushchego inzhenera [Research of the information needs of the future engineer]. In Sbornik materialov Vserossijskoi studencheskoi nauchnoi konferentsii s Mezhdunarodnym uchastiem: v 3 chastyah: «STUDENT: NAUKA, PROFESSIYA, ZHIZN» [Collection of Materials of the V All-Russian student scientific conference with international participation: in 3 parts «STUDENT: SCIENCE, PROFESSION, LIFE»]. Omsk, 254-257.

Khekalo, E.E. (2015). Klassifikatsiia informatsionno-matematicheskih modelei [Classification of information-mathematical models]. In Nauchno-metodicheskij elektronnyj zhurnal «Koncept» [Scientificmethodical electronic journal «Concept»], 13, 886-890, available at: http://e-koncept.ru/2015/85178.htm (accessed 16 July 2019)

Klarin, M.V. (2018). Innovacionnye modeli obucheniya. Issledovaniya mirovogo opyta [Innovative learning models. The study of the world experience]. Moscow, LUCH, $640 \mathrm{p}$.

Krasavina, Iu.V., Shikhova, O.F. (2017). Metod elektronnyh mezhdistsiplinarnyh proektov kak effektivnaia forma organizatsii samostoyatel'noi raboty studentov vuza [Method of electronic interdisciplinary projects as an effective form of organization of independent work of University students]. In Obrazovanie i nauka [Education and Science], 19 (1), 160-176. DOI: 10.17853/1994-5639-2017-1-160-176

Mogilev, A.V., Pak, N.I., Khenner, E.K. (2012). Informatika [Informatics]. Moscow: Izdatel'skii tsentr «Akademiia», $848 \mathrm{p}$.

Moiseeva, N.A., Poliakova, T.A. (2018). Mezhpredmetnye sviazi matematiki i informatiki v sisteme nepreryvnogo inzhenernogo obrazovaniia [Interdisciplinary connections of mathematics and Informatics in the system of continuous engineering education]. In Nauka o cheloveke: gumanitarnye issledovaniia [The Science of Person: Humanitarian Researches], 1 (31), 85-93. DOI: 10.17238/issn1998-5320.2018.31.85

Moiseeva, N.A. (2018). Sovremennyi vzgliad na nauchno-issledovatel'skuiu rabotu studentov po informatike $\mathrm{v}$ sisteme nepreryvnogo inzhenernogo obrazovaniia [A modern view on the research work of students in computer science in the system of continuous engineering education]. In Sbornik nauchnyh trudov nacional'noi nauchno-prakticheskoi konferencii "Obrazovanie. Transport. Innovacii. Stroitel'stvo» [Collection of scientific papers of the national scientific and practical conference: "Education. Transport. Innovations. Construction»], Omsk, 681-684.

Monica, C. (2019). Mathematical Modeling in Engineering Design Projects: Insights from an Undergraduate Capstone Design Project and a Year-Long Graduate Course. Available at: https://www.researchgate.net/publication/267242510_Mathematical_Modeling_in_Engineering_Design_Projects_Insights_ from_an_Undergraduate_Capstone_Design_Project_and_a_Year-Long_Graduate_Course (accessed 24 May 2019)

Nastashchuk, N.A., Poliakova, T.A. (2017). Znachimost' vuzovskogo kursa discipliny «Matematika» v discipline «Bnformatika» dlia budushchih inzhenerov transportnoi otrasli [The significance of the university course of the discipline «mathematics» in the discipline «informatics» for future engineers of the transport industry]. In Nauka o cheloveke: gumanitarnye issledovaniia [The Science of Person: Humanitarian Researches], 1(27), 132-140. DOI 10.17238/issn1998-5320.2017.27.132.

Nosko, I.V. (2011). Studentotsentrirovannoe obrazovanie kak osnovopolagayushchii printsip Bolonskih reform v vysshei shkole [Student-centered education as a fundamental principle of Bologna reforms in higher education]. In Vektor nauki Tol'iattinskogo gosudarstvennogo universiteta. Seriia: Pedagogika, Psihologiia [Science Vector of Togliatti State University. Series: Pedagogy, Psychology], 1(4), 135-138. 
Noskov, M.V., Popova, V.V. (2015) Realizatsiia mezhpredmetnyh svyazei matematiki i informatiki v sovremennom uchebnom processe [The implementation of interdisciplinary connections of mathematics and information science in modern educational process]. In Vestnik Krasnoiarskogo gosudarstvennogo pedagogicheskogo universiteta im. V.P. Astaf'eva [Bulletin of Krasnoyarsk State Pedagogical University V.P. Astafiev], 1 (31), 65-68, available at: https://cyberleninka.ru/article/n/realizatsiya-mezhpredmetnyhsvyazey-matematiki-i-informatiki-v-sovremennom-uchebnom-protsesse

Pak, N.I., Doroshenko, E.G., Hegai L. B. (2015). O neobhodimosti i vozmozhnosti organizatsii lichnostno tsentrirovannogo obucheniia v vuze [On the necessity and possibility of organizing personality-centered education at a university]. In Pedagogicheskoe obrazovanie v Rossii [Pedagogical education in Russia], 7, 16-23.

Pak, N.I., Doroshenko, E.G., Hegaj, L.B. (2017). Organizatsiia student-tsentrirovannogo obucheniia studentov informatike na osnove uchebnyh dorozhnyh kart [Organization of student-centered teaching of computer science students on the basis of educational road maps]. In Nizhegorodskoe obrazovanie [Nizhny Novgorod education], 1, 56-65.

Perminov, E.A., Gadzhiev, D.D., Abdurazakov, M.M. (2019). Ob aktual'nosti fundamentalizatsii matematicheskoi podgotovki studentov pedagogicheskih napravlenii $\mathrm{v}$ tsifrovuiu epohu [About the relevance of fundamentalizing the mathematical preparation of students in pedagogical areas in the digital age]. In Obrazovanie i nauka [The Education and Science Journal], 21(5), 87-112. DOI: 10.17853/1994-56392019-5-87-112

Prikhod'ko, V.M., Solov'iev, A.N. (2013). IGIP i tendentsii inzhenernoj pedagogiki v Rossii i v mire [IGIP and tendencies of engineering pedagogy in Russia and in the world]. In Vysshee obrazovanie $v$ Rossii [Higher Education in Russia], 6, 26-32.

Rodionov, M.A., Fedoseev, V.M., Ledovets, Zh., Shabanov, G.I., Akimova, I.V. (2018). Osobennosti proektirovaniia tekhnologicheskogo komponenta integrirovannoi metodicheskoi sistemy matematicheskoi podgotovki budushchih inzhenerov [Features of design of technological component of integrated methodical system of mathematical training of future engineers]. In Integraciya obrazovaniya [Integration of Education], 22 (2), 383-400. DOI: 10.15507/1991-9468.091.022.201802.383-400

Salleh, T.S, Zakaria, E. (2016). The Effects of Maple Integrated Strategy on Engineering Technology Students' Understanding of Integral Calculus. In The Turkish Online Journal of Educational Technology, 15 (3), 183-194, available at: https://files.eric.ed.gov/fulltext/EJ1106377.pdf (accessed 24 July 2019)

Samarskii, A.A., Mikhailov, A.P. (2005). Matematicheskoe modelirovanie: Idei. Metody. Primery [Mathematical modeling: Ideas. Methods. Examples]. Moscow: FIZMATLIT, 320 p.

Sovetov, B. Ia., Sovetov, S. Ia. (2017). Modelirovanie sistem [Modeling of systems]. Moscow: Iurait, $343 \mathrm{p}$.

Student-Centred Learning. Toolkit for students, staff and higher education institutions. - ESU. Brussels, October (2010). Available at: https://www.esu-online.org/wp-content/uploads/2017/10/SCL_toolkit_ ESU_EI.compressed.pdf (accessed 15 June 2019)

Taajamaa, V., Airola, A., Pahikkala, T., Salakoski, T., Eskandari, M., Karanian, B. (2016). O-CDIO: Emphasizing Design Thinking in CDIO Engineering Cycle. In International Journal of Engineering Education, 32 (3), 1530-1539, available at: https://www.researchgate.net/publication/305045559_OCDIO_Emphasizing_Design_Thinking_in_CDIO_Engineering_Cycle (accessed 11 July 2019)

Vaganova, O.I., Iliashenko, L.K. (2018). Osnovnye napravleniia realizatsii tekhnologii studentotsentrirovannogo obucheniia $\mathrm{v}$ vuze [The main directions of the implementation of student-centered learning technologies in the university]. In Vestnik Mininskogo universiteta [Bulletin of the Minin University], 6(3), 2. DOI: $10.26795 / 2307-1281-2018-6-3-2$

Vaganova, O.I., Prohorova, M.P., Karpova, M.A. (2019). Realizatsiia studentocentrirovannogo obucheniia $\mathrm{v}$ vysshem uchebnom zavedenii [Implementation of student-centered learning in a higher educational institution]. In Karel'skii nauchnyi zhurnal [Karelian Scientific Journal], 2(27), 56-58. DOI 10.26140/ knz4-2019-0802-0014. 
Vainshtein, Iu. V. Shershneva, V.A., Safonov, K.V. (2016). Ideologiia CDIO v obuchenii matematike [Ideology of CDIO in teaching mathematics]. In Vysshee obrazovanie v Rossii [Higher education in Russia], $2,75-82$.

Verbiczkii, A.A. (2010). Kontekstno-kompetentnostnyi podhod k modernizatsii obrazovaniia [Contextcompetency-based approach to the modernization of education]. In Vysshee obrazovanie v Rossii [Higher education in Russia], 5, 32-37.

Wright, G.B. (2011). Student-Centered Learning in Higher Education. In International Journal of Teaching and Learning in Higher Education, 23 (3), 93-94.

Yasseri, Dar, Finley, Patrick M., Mayfield, Blayne E., Davis, David W., Thompson, Penny, Vogler, Jane S. (2018). The hard work of soft skills: augmenting the project-based learning experience with interdisciplinary teamwork. In Instructional Science, 46 (3), 457-488. DOI: 10.1007/s11251-017-9438-9

Zabalawi, I. (2018). Engineering Education for the Future World: The CDIO Approach, pp. 102, available at: http://www.cdio.org/files/document/file/Engineering\%20Education $\% 20$ for $\% 20$ the $\% 20$ Future $\% 20$ World\%20-\%20The\%20CDIO\%20Approach.pdf (accessed 11 July 2019)

Zagvyazinskiy, V.I. (2006). Teoriia obucheniia: sovremennaia interpretatsiia: uchebnoe posobie [Theory of learning: modern interpretation]. Moscow: Academiia, $192 \mathrm{p}$. 